\title{
INTEGRATED DEVELOPMENT OF PRODUCTS AND SERVICES
}

\author{
Karin Auernhammer, Matthias Stabe \\ Fraunhofer Institute for Industrial Engineering \\ Karin.Auernhammer@iao.fhg.de \\ Matthias.Stabe@iao.fhg.de
}

\begin{abstract}
This article focuses on innovation patterns in product-service systems and presents a conceptual framework for the integrated development of products and services. Traditionally, research in innovation patterns has dealt primarily with manufacturing systems. Since the early eighties, service innovation and its impact on economic growth increasingly went into focus of scientific interest. Although more comprehensive, commonly accepted, concepts still remain to be elaborated, innovative solutions in manufacturing and services - especially in product-service systems - can be argued to show an increasing tendency towards pattern convergence. This hypothesis results in the research question how the integrated development of products and services impacts the innovation systems of companies.
\end{abstract}

\section{INTRODUCTION}

Recent investigations into growth patterns in companies did not merely point on efficiency increase - achieved intensively or extensively - in production processes but emphasized changing roles of innovation and fast technology progress as key drivers, too (OECD, 2000). On a macro-economic level, this was as well revealed by the research results of Romer (Romer, 1995): after investigating various differing national growth rates he developed a "new growth theory", stating that differences in growth patterns cannot be explained by natural resources and capital goods alone anymore, but rather by ideas and knowledge resulting in innovation.

Innovation does not only relate to new products or technically advanced or superior systems, but increasingly covers intangible aspects in the corporate product and service portfolios, too. In contexts of international competition, successful companies gain decisive advantage not only by cost-leadership, quality or traditional technology, but in particular by differentiation through innovative products offering value-added services. The relationship between services and manufacturing seems to have changed in the last years (Miles, 2000). Many companies perceive themselves not only as product-oriented, but more and more as solution-oriented, which implies services as intrinsic parts of solutions (OECD, 2000). Consequently, simultaneous development of products and services for perceivable combination of tangible and 
intangible assets gains increasing importance. In this, services form not only add-ons to products, but strike as valuable part in the value proposition of a company.

An approach for integrated development of products and services is meant on the one hand to overcome the traditional difficulties in investigating the growth patterns of manufacturing and service industry. On the other hand, the purpose of the approach is to provide a sound methodological framework and toolset for companies managing their product-service system.

\section{PECULARITIES AND CHARACTERISTICS OF INNOVATION PROCESSES IN PRODUCTS AND SERVICES}

\subsection{Innovation in Manufacturing}

Traditionally, innovation research has been focused on manufacturing industries. Accordingly, the Oslo Manual of OECD (OECD, 1992) defined innovation in the following way:

"Technological innovations comprise new products and processes and significant technological changes of products and processes. An innovation has been implemented if it has been introduced on the market (product innovation) or used within a production process (process innovation). Innovations therefore involve a series of scientific, technological, organization, financial and commercial activities."

Furthermore, OECD differentiates between major and incremental product innovation.

Innovation in manufacturing industry is mainly driven by new technologies or new materials applied in production processes or products. Due to predominantly technological orientation, the innovation function is organizationally realized by R\&D departments that implement new technologies or materials in products and /or processes. The overall objective for product innovation is a superior competitive position in the relevant market. Accordingly, new products or production processes aim strategically either on cost-reduction or functional improvements. The relevant knowledge incorporated into a new product or a new production process can be protected by patents.

\subsection{Innovation in Services}

Innovations in services show specific characteristics, that primarily relate to specific characteristics of services. They can according to Hipp (Hipp et al., 2000; Sirilli and Evangelista, 1998) be described as

- Close interaction between production and consumption

- High information content and the intangible nature of service output

- The key role of human resources in the pro-vision of services

- Critical role of organizational factors in firms performance

In contrast to the rather homogeneous essential nature of services, the service sector itself shows a great heterogeneity with respect to output composition, branches, processes or company size. Furthermore, a number of sectors are still regulated while others are relatively open with low barriers of entry and keen competition (OECD, 2000). 
Many authors (such as Preissl, 2000; Soete and Miozzo, 1989) argue that traditional innovation indicators are not applicable to investigate the characteristics and implications of service innovations. Moreover, they emphasize upon differences between manufacturing and service innovations in organizational design, process, impetus and general management models. The provision of services as well as the cost structure show significant differences to those in manufacturing (Preissl, 2000). While knowledge-based services do not require large investment in early phases of development, other types of services such as scale-intensive physical networks (Soete and Miozzo, 1989) require investments to a large extent. This limits the value of using investment figures for innovation measurement. Furthermore, services put a high emphasis on intellectual capital which is difficult to measure. The quality of service innovation output as a measure for productivity growth, as well as a proper differentiation between product and process innovation for services are major elements of difference, too. Furthermore, $R \& D$ in service sectors is only rarely comparable to manufacturing as it mostly spreads over all actors and is not located in a specific group of actors or a department. Therefore, the R\&D expenditure is difficult to measure and the protection of knowledge by patents does not seem appropriate for services as well.

\section{DETERMINANTS AND TYPOLOGY OF INNOVATIONS IN PRODUCT-SERVICE-SYSTEMS}

\subsection{Relations between Products and Services}

Besides the differences in characteristics of manufacturing and service innovation, however, convergence of innovation patterns of products and services is recognizable with several respects. For example, some key factors such as appropriation of knowledge, learning organization or changing qualification needs do not differ significantly. However the knowledge intensity and the strong emphasis on human factors and skills still differentiate most service innovation from manufacturing innovations.

The interactive nature of information and communication technologies (ICT) changes the way in which economic agents exchange - virtual and real - value information (Antonelli, 2000). Preissl (Preissl, 2000) points on the importance of ICT use on modularization and standardization potentials in services. New technologies change services in ways increasingly similar to those in manufacturing in the past (Licht et al., 1999); e.g. services types that traditionally were provided by human agents are automated through technology applications such as self-service terminals etc. Products and services seemingly depend on each other in particular with respect to the increasing implementation of ICT.

Although these signs of convergence do not erase the major differences between manufacturing and service innovation patterns the arguments above show that both concepts have as well similar features. Due to their heterogeneity, though, the specific relations between products and services cause challenges and obstacles for establishing an integrative framework that require more detailed investigation. 


\subsection{Business Models}

Within the context of combining innovations in products and services, several development opportunities for related business models can be identified:

- First is that an enterprise with products innovates via adding services to the former on their own

- Second is that a service provider refers to a "platform" product to develop and market a specific service that adds value to this product

- Third is that both the product manufacturer and the service provider bundle forces in concurrently optimizing and innovating their respective tangible or intangible offer to the other.

- Fourth would be alliances of inter-dependent services

Within these different (general) types of product-service relations, the innovation impetus derives from the focus of main business activity.

To identify patterns of innovation in service industries, (Den Hertog, 2000) suggested observation of specific inter-relations between a) supplier of - technical as well as non-technical - innovation input, b) individual service firm and c) type of clients of innovative service (intermediate - manufacturer or service provider - or final user). Subsequently five patterns were presented:

- (Product-) supplier-dominated innovation

- Innovation in service (calling onto product innovation)

- Client-led innovation (calling both product as well as service innovation)

- Innovation through service (e.g. knowledge-intensive)

- $\quad$ Paradigmatic innovation (completely new product \& service system model)

According to these types, specific innovation processes and related organizational models can be established. As is obvious, furthermore, holistic understanding of product-service solutions is required for appropriate business design.

\section{CONCEPTUAL FRAMEWORK FOR INTEGRATED DEVELOPMENT OF PRODUCTS AND SERVICES}

\subsection{Concept Fundamentals}

The research project "Pro(duct) Se(rvi)c(e) Co-(design)" (also: ProSecCo, PSCD) combines research partners and other solution providers as well as industrial partners from several European countries. For the conceptual framework for above project, it was understood that holistic solutions to customer demands require conception spaces that extend beyond mere product or service innovation models. Consequently, the initial framework was conceived as set of qualitative and quantitative entrepreneurial goals and content interests, based on interrelations of products and services as perceived by both customers and providers. As the emphasis here laid on socio-economic issues rather than on (e.g. technological) instrumental means, the initial concept was then detailed in more practical terms of market, product \& service, technology etc. This resulted in a model for design of product-service systems as shown in Figure 1 below. Integrated conception of product-service system architectures is understood to be an integrative cluster of at least partially iterative processes, involving multiple technical and non-technical 
issues and requiring continuous scanning of business environments in multidimensional way (following innovation patterns as mentioned in chapter 3 already).

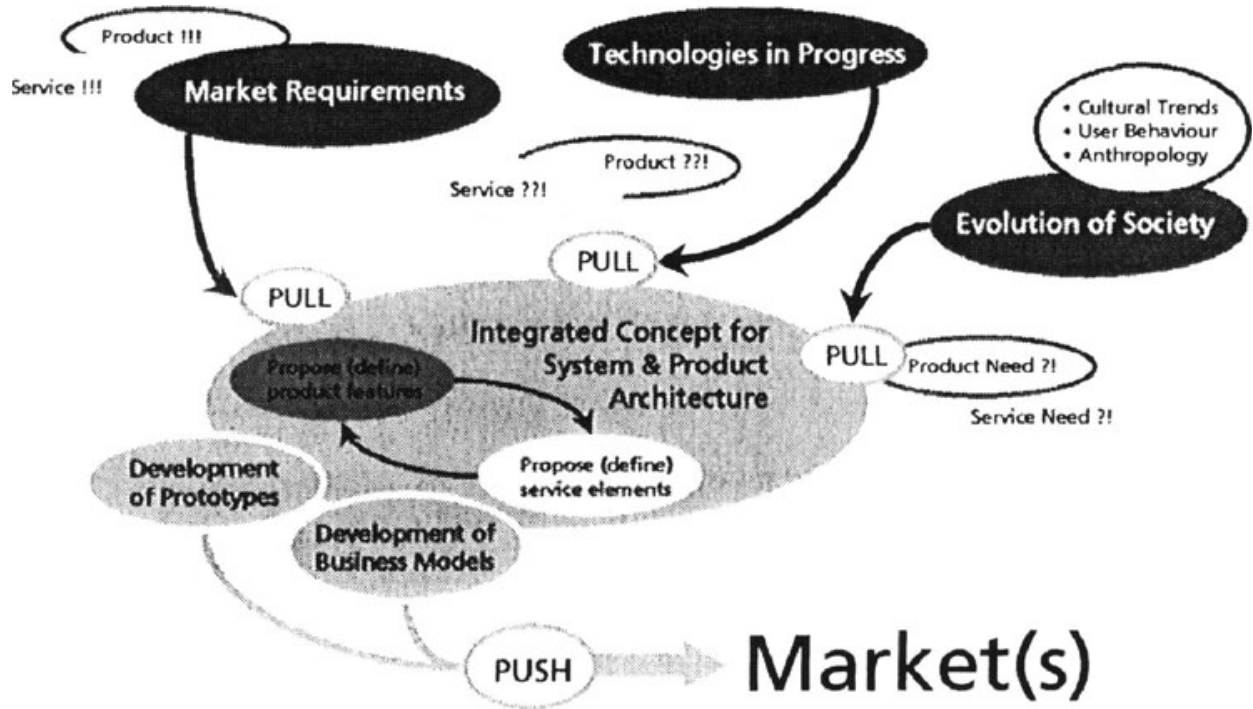

Figure 1 - Product-service system innovation scheme

The ProSecCo industrial partners relate to three industrial clusters - "Culture and Entertainment", "Medical Technology and Applications", and "Health Care and Food Safety" - where co-development of product and services is of increasing importance and where, due to the cross-border markets and competition for products and services, transnational collaboration has become critical for success. Industrial partners from small and medium companies (SME) participate, with different levels achieved in implementing ICT, experience in inter-company collaboration and working in production development, innovation management etc.

In the current article, the third of the clusters above shall be described. Here SMEs typically form chains of companies providing electronic control equipment for quality surveillance, transportation and tracking, related maintenance, handling and packaging etc. of perishables. Thus, product-service hybrid innovation has to realize interrelating functionalities by means of structures in space and / or time (see Figure 2). Food safety and health care are perceived as issues differing mainly with regard to aspects of security standards and scales. Firstly, this may imply that rather simple products have to be combined with peculiar, if complex, services to fasten the logistics as well as the management of mass (eg. food) or very low lot (eg. synthetic or organic implants) production. Secondly, to offer a value proposition may include assistant functionality to be realized by rather specific technical PSCD innovation. Additionally, Figure 2 reveals that product-service innovation implies and cross-branch, cross-sectoral collaboration efforts. For this reason, it is proposed to group networks according to related solution themes rather than along traditional branch or sector models. Therefore, the chosen approach refers to networks of product manufacturers and service providers belonging to different typologies of innovation impetus as presented in chapter 3 . 


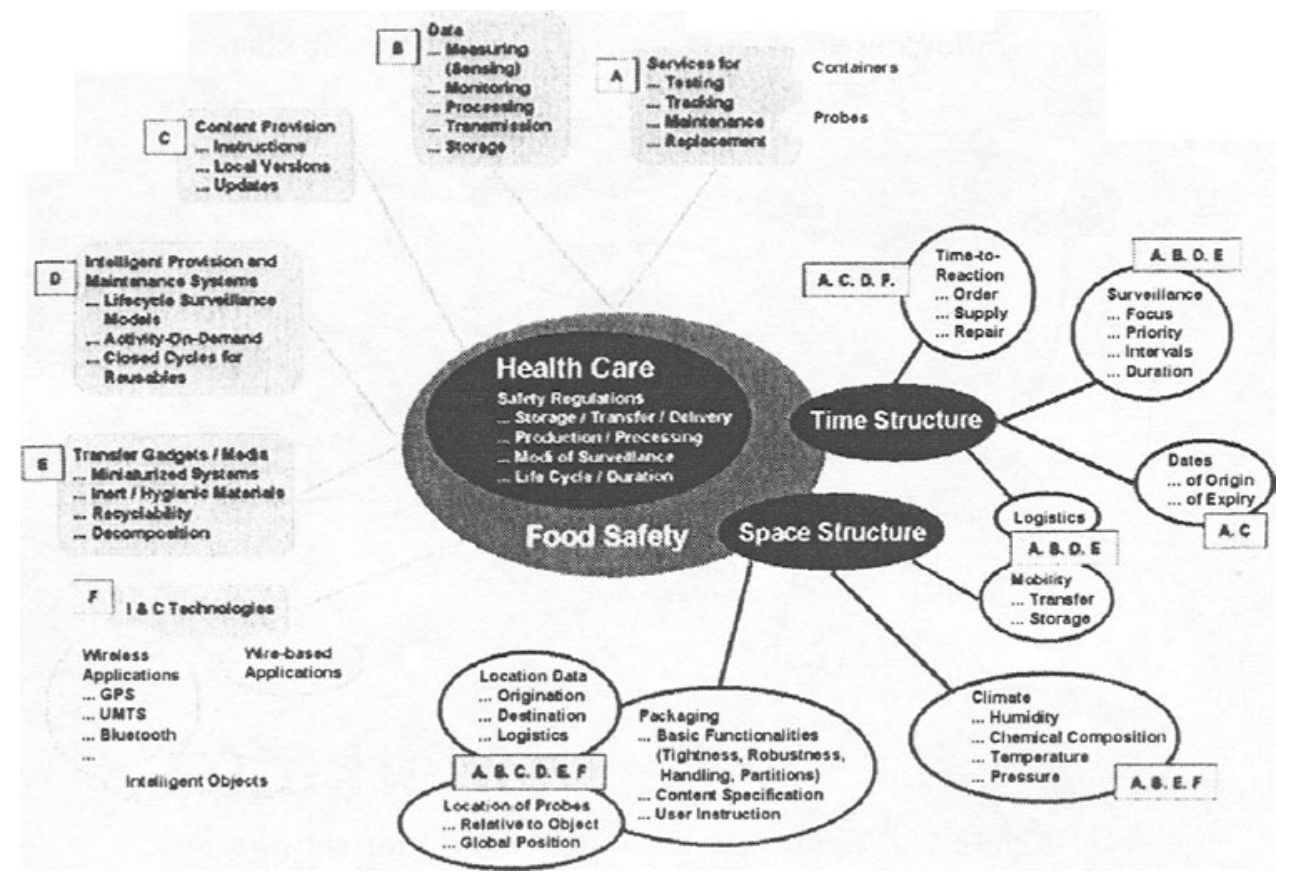

Figure 2 - Potential product-service network in the area of "Health Care and Food Safety"

Finally, solution spaces as depicted in Figure 2 shall encourage entrepreneurial creativity in SMEs to further evolve current business profiles or to forge strategic alliances in areas of (future) interest.

\subsection{Dimensions of Convergence}

In the following, first thoughts of a conceptual framework of an integrated approach for innovation in product-service systems are presented. It is based on hypotheses still to be tested and refined within the ongoing research in this field.

The approach is based on the convergent factors of technology and knowledge related to products and services. The strategic context forms an overall framework for the integration. The concept refers to Hertogs four-dimensional model of service innovation (Hertog, 2000), but focuses upon linking dimensions in product-service systems that are fundamental to an integrated approach.

Dimension 1: The value proposition concept

The composition of product and services within a system constitutes the value proposition that the company or the network is offering: to provide a solution to a specific customer problem implies combining tangible and intangible elements. In fact, integrated development of product and service systems is likely to cause shifts in corporate image and strategy regarding the means to create value for customers because holistic problem solutions must cover tangible and intangible components in a manner appropriate to corporate economical interests as well as responding the 
customer (or market) needs in best-possible way. Business design is required to cover both relevant contents as well as establishment of networks of partners with complementary competences (e.g. related to branch / sector models) required for holistic problem solutions. Accordingly, business strategies and - in particular - the development methods have to focus product and service issues integratively, too.

Dimension 2: Product and service system interface and technological options Whereas an increased demand for customer-tailored products leads to incorporation of services in products (e.g. remote maintenance), other solutions feature specific service models that may require particular hardware for being enabled / delivered to final customers (e.g. location-based information services). In both cases, technology significantly shapes the area of intersection between a system's particular products and services. While large companies may be capable of developing those subsystems integrally, SMEs intending to establish equivalent cross-branch, interorganizational competence and strategic networks need to set-up the functional and content-related interfaces between their particular ranges of contribution in ways that both result in sufficient critical mass for setting new standards as well as open chances for further "plug-ins" solving specific problems of other final users innovatively but within a particular product - service system's paradigm. Whereas dimension 1 relates to the system interface for relations to the (external) customer, the current dimension affects more the internal routines and specifications that finally enable an integrated product-service system at all. This, of course, strongly affects organizational design as well. The flexibility of a company to meet various specifications and openness to technological progress or shifts constitutes a competence area critical for success. Technology forming a link between product and service, is not only required to focus requirements of final user but also those of service partners. This widens e.g. the set of criteria for assessing alternatives.

Dimension 3: Role of knowledge

Bodies developing value propositions via specific composition of products and services into systems inevitably have to establish and manage the competences (capabilities in terms of resources, processes and values (Christensen, 2000)) required in the related business models. In doing so, critical knowledge regarding technologies, delivery and applications is developed through interaction both internal of the value-creating network and - even more important - through its direct encounters with final customers (as the very way of delivering services). Due to the tacit nature of knowledge involved in developing and delivering services, management methodology as well as ICT-based tools addressing the issues above strongly rely on the "human factor" to become supportive at all. Especially knowledge-intensive services form a critical link between products and services. within a product-service system

\section{CONCLUSION}

Based on considerations of research in the innovation patterns in manufacturing and service industries, the current work proposes a conceptual framework for integrated design of products and services in terms of proposing more holistic solutions. The 
presented approach in particular relates to the convergent factors of technology and knowledge and conceptually incorporates the dimensions of value proposition, system interface design and role of knowledge. To successfully develop productservice systems, companies are required to adopt a holistic solution perspective and to consider implications for managerial practice regarding strategic issues of business development (emergent versus intended approaches), organizational design to achieve necessary capabilities in terms of networking adaptiveness and efficient innovation processes. These issues need to be further investigated by combining expertise from various fields of expertise such as service engineering, design and innovation management, $R \& D$ management and advanced marketing.

\section{ACKNOWLEDGEMENTS}

This work has been sponsored by the European Commission through the Growth Project No. G1RD-CT-2002-00716: ProSecCo, "Product \& Service Co-Design". The authors wish to acknowledge the Commission for its support as well as all the ProSecCo project partners for their contribution during the development of ideas and concepts presented in this paper. However, the text presented here is in the sole responsibility of the authors and the usual disclaimers apply.

\section{REFERENCES}

1. Antonelli C. Recombination of the production of technological knowledge: some international evidence. In Melcalfe JS, Miles I. Innovation Systems in the Service Economy. Measurement and Case Study Analysis. Boston /Dordrecht /London: Kluwer Academic Publ., 2000.

2. Christensen, Clayton M. The Innovators Dilemma, New York: HarperCollins Publ. Inc., 2000.

3 Hertog den P. Knowledge-Intensive Business Services as Co-Producers of Innovation. In International Journal of Innovation Management, Vol.4 No.4 (Dec 2000), pp. 491-528

4. Hipp et al.. The incidence and effects of innovation in services: Evidence from Germany. In Journal of Innovation Management. Vol. 4, No. 4 (December 2000): pp. 417-453.

5. Licht et al.. Innovation in the service sector - selected facts and some policy conclusions. Mannheim: Center for European Economic research, 1999.

6. Miles, I. Service Innovation: Coming Age in the Know-ledge-based Economy. In Journal of Innovation Management. Vol. 4, No. 4 (December 2000): pp. 371-389.

7. Melcalfe JS, Miles I. Innovation Systems in the Service Economy. Measurement and Case Study Analysis. Boston /Dordrecht/London: Kluwer Academic Publ., 2000.

8. OECD. Proposed Guidelines for collecting and interpreting technological innovation data - Oslo Manual 1992.

9. OECD. The Service Economy, Business and Industry Policy Forum, 2000. http://www.oecd.org/dsti/sti/industry/indcomp/act/services/forum.htm

10. Preissl B. Service innovation: what makes it different? Empirical evidence from Germany. In Metcalfe JS, Miles I. Innovation Systems in the Service Economy. Measurement and Case Study Analysis. Boston /Dordrecht /London: Kluwer Academic Publ., 2000.

11. Romer, P.M. (1995) Economic Growth The Fortune Encyclopedia of Economics, David R. Henderson (ed.)

12. Sirilli G, Evangelista $R$. Technological innovation in services and manufacturing: Results from an Italian survey. In Research policy Vol. 27 (1998), No. 9, pp. 881-899.

13. Soete L, Miozzo M. Trade and development in services: a technological perspective. In MERIT Report 89-031, Maastricht: MERIT, 1989.

14. Ramaswamy R. Design and Management of Services processes. Keeping Customers for Life. Reading MA: Addison-Wesley Publ. Comp., 1996. 